\title{
Controlling Ion Conductance and Channels to Achieve Synaptic- like Frequency Selectivity
}

\author{
Siheng Lu $\cdot$ Fei Zeng $\cdot$ Wenshuai Dong $\cdot$ Ao Liu $\cdot$ Xiaojun Li $\cdot$ Jingting Luo
}

Received: 28 September 2014/ Accepted: 18 November 2014/Published online: 16 December 2014

(C) The Author(s) 2014. This article is published with open access at Springerlink.com

\begin{abstract}
Enhancing ion conductance and controlling transport pathway in organic electrolyte could be used to modulate ionic kinetics to handle signals. In a Pt/Poly(3-hexylthiophene-2,5-diyl)/Polyethylene $+\mathrm{LiCF}_{3} \mathrm{SO}_{3} / \mathrm{Pt}$ hetero-junction, the electrolyte layer handled at high temperature showed nano-fiber microstructures accompanied with greatly improved salt solubility. Ions with high mobility were confined in the nano-fibrous channels leading to the semiconducting polymer layer, which is favorable for modulating dynamic doping at the semiconducting polymer/electrolyte interface by pulse frequency. Such a device realized synaptic-like frequency selectivity, i.e., depression at low frequency stimulation but potentiation at high-frequency stimulation.
\end{abstract}

Keywords Ions migration · Nano-channels · Frequency selectivity $\cdot$ Semiconducting polymer $\cdot$ Organic electrolyte Dynamic doping

\section{Introduction}

Ion transportation in organic electrolyte has been widely studied, especially in the field of advanced energy [1]. State of electrolyte and ion conductance influenced significantly performance of ion battery [2]. Early study indicated that ion conductivity had contributions from both anions and cations when the electrolyte was amorphous [3]. Since working voltage is usually high in ion battery, ion transport couples strongly with polymer segments in kinetics and then high ionic mobility along fixed direction is required to weaken this coupling $[4,5]$. Thus, crystalline polymer

S. Lu $\cdot$ F. Zeng $(\varangle) \cdot$ W. Dong $\cdot$ A. Liu $\cdot$ X. Li

Laboratory of Advanced Materials (MOE), School of Materials

Science and Engineering, Tsinghua University, Beijing, People's

Republic of China

e-mail: zengfei@mail.tsinghua.edu.cn

J. Luo $(\square)$

Institute of Thin Film Physics and Applications, Shenzhen Key

Laboratory of Sensor Technology, Shenzhen University,

Shenzhen, People's Republic of China

e-mail: luojt@szu.edu.cn electrolyte was proposed and fabricated to enhance ionic conductivity, in which ions could move in designed channels quickly [6]. Some study demonstrates the ionic pathway control by 3D network design [7].

In this paper, we focused on how electrolyte-based device behaves under small input in a situation of directional ionic channels formed, and how that can be related to information handling. We have found a synaptic-like frequency selectivity, a frequency dependent response transformed between depression to potentiation, of $\mathrm{Pt} / \mathrm{Poly}$ (3-hexylthiophene-2,5diyl) (P3HT)/Polyethylene ( $\mathrm{PEO})+\mathrm{LiCF}_{3} \mathrm{SO}_{3} / \mathrm{Pt}$ cell in previous study [8]. This device could be applicable to signal handling and synaptic computation, such as filtering and decoding. Compared with those memristors simulating synaptic plasticity, which is a popular research topic in the fields of informatics, materials, and neuroscience [9-13], our cell owns several advantages. For example, ions are working substances, dynamic doping is reversible, and power consumption is low. Therefore, this type of device has great potential to be artificial synapse for brain-like computation [14]. We further studied microstructure of this device in this paper and found that ions migration along directional channels was a necessary factor to obtain frequency selectivity. 


\section{Experimental}

Substrates $(1.2 \times 1.2 \mathrm{~cm})$ were cut from the commercially available $\mathrm{Si} / \mathrm{SiO}_{2}(300 \mathrm{~nm}) / \mathrm{Ti}(20 \mathrm{~nm}) / \mathrm{Pt}(150 \mathrm{~nm})$ wafers, in which Pt $(150 \mathrm{~nm})$ was used as the bottom electrode (BE). The substrates were cleaned using ultrasonic waves in a sequence of acetone, ethyl alcohol, deionized water, and ethyl alcohol, then dried using a stream of nitrogen gas and stored in a nitrogen atmosphere glove box. Poly(3hexylthiophene-2,5-diyl) (P3HT) was purchased from Zhejiang Optical \& Electronic Technology Co. Ltd. Polyethylene (PEO) $\left(\mathrm{MW}=100,000 \mathrm{~g} \mathrm{~mol}^{-1}\right)$ and lithium trifluoromethanesulfonate $\left(\mathrm{LiCF}_{3} \mathrm{SO}_{3}\right)$ were purchased from Sigma-Aldrich Co. and used as received. P3HT was dissolved in 1, 2-dichlorobenzene to form a $0.5 \mathrm{wt} \%$ solution and stirred on a magnetic hot plate at $40{ }^{\circ} \mathrm{C}$ for $12 \mathrm{~h}$. Then $3.5 \mu \mathrm{L}$ of the P3HT solution was spin-coated on the BE at $500 \mathrm{rpm}$ for $10 \mathrm{~s}, 3,000 \mathrm{rpm}$ for $30 \mathrm{~s}$, and then $1,500 \mathrm{rpm}$ for $20 \mathrm{~s}$. After spin-coating, the P3HT layer was dried on a hot plate at $100{ }^{\circ} \mathrm{C}$ for $1 \mathrm{~h}$ then at $142{ }^{\circ} \mathrm{C}$ for 20 min. The resulting P3HT film had a thickness of $30-50 \mathrm{~nm}$. The electrolyte solution was prepared by dissolving $\mathrm{PEO}$ in deionized water at a concentration of $2 \mathrm{wt} \%$ and adding $\mathrm{LiCF}_{3} \mathrm{SO}_{3}$ to yield a molar ratio of $16: 1$ $\mathrm{EO}: \mathrm{Li}^{+}$. The electrolyte solution was stirred for $12 \mathrm{~h}$ on a magnetic hot plate at $40{ }^{\circ} \mathrm{C}$. The electrolyte layer was prepared by drop-casting $4 \mu \mathrm{L}$ of the electrolyte solution on the as-prepared P3HT film, and then annealed on a hot plate at 40 or $100{ }^{\circ} \mathrm{C}$ for $20 \mathrm{~min}$. A Pt top electrode (TE) with a thickness of $70 \mathrm{~nm}$ was deposited by the electronbeam evaporation with a rate of $0.3-0.5 \AA \mathrm{s}^{-1}$ through a shadow mask. A schematic of the device structure is shown in Fig. 1a.

Current-voltage $(I-V)$ sweeps and pulse responses were measured using an Agilent B1530A waveform generator by connecting the $\mathrm{BE}$ and $\mathrm{TE}$. For all measurements, the $\mathrm{BE}$ was grounded. The ambient temperature was around $26{ }^{\circ} \mathrm{C}$ and the relative humidity was about 60 during measurement. Raman spectra of the polymer films were obtained using a HR-800 Raman system. A $532 \mathrm{~nm}$ HeNe laser was used as the excitation source; and had a resolution of $1.32 \mathrm{~cm}^{-1}$.

\section{Results and Discussion}

After the electrolyte solution was drop-cast on the as-fabricated P3HT film, the film was annealed at either 40 or $100{ }^{\circ} \mathrm{C}$. For convenience, we named the cells made at 40 and $100{ }^{\circ} \mathrm{C}$ the low temperature cell (LTC) and high temperature cell (HTC), respectively. Figure $1 \mathrm{~b}$ and $\mathrm{c}$ show the direct $I-V$ relationship for these two cells with a voltage sweep rate of $100 \mathrm{~V} \mathrm{~s}^{-1}$. Conventional hysteresis loops were observed due to ion migration in the electrolyte. The residual current at $V=0$ indicated that the ion current fell behind the voltage sweep rate. There are apparent differences between the $I-V$ curves of the LTC and HTC. In the HTC, the absolute current was higher and the hysteresis loop was larger. Particularly, a negative differential resistance (NDR) was observed during the positive sweep for the HTC but not for the LTC (Fig. 1b). We supposed that the NDR resulted from the differences in ion mobility at the $\mathrm{P} 3 \mathrm{HT} / \mathrm{PEO}+\mathrm{LiCF}_{3} \mathrm{SO}_{3}$ interface. $\mathrm{Li}^{+}$ions moved through the interface under positive bias and accumulated to form an opposite electric field, which caused a current drop when the loaded bias reached the peak of the NDR. The current rise before NDR corresponded to ions doping into the P3HT layer, that during NDR corresponded to ions de-doping, and that after NDR corresponded to ions redoping due to stronger loaded electric field. In addition, the current of the HTC was quite higher than that of LTC, suggesting that ion conductivity was higher in HTC. Both the low conductivity and absence of NDR for the LTC indicated the lack of effective or activated ions in the PEO layer.

In order to find microstructure base accounting for the difference in Fig. 1, we examined photomicrographs and scanning electron microscope (SEM) images of the

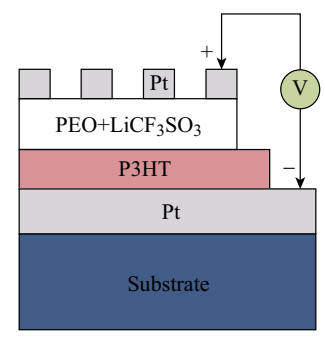

(a)

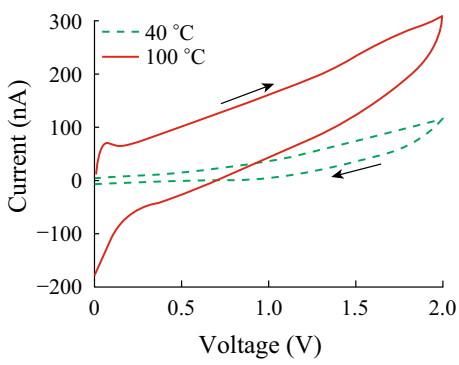

(b)

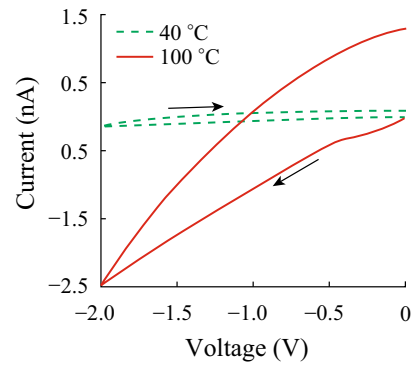

(c)

Fig. 1 a Schematic of the Pt/P3HT/PEO $+\mathrm{LiCF}_{3} \mathrm{SO}_{3} / \mathrm{Pt}$ cell. Current-voltage $(I-V)$ curves: where the sweeping direction was b $0 \rightarrow 2 \rightarrow 0 \mathrm{~V}$ and; $\mathbf{c} 0 \rightarrow-2 \rightarrow 0 \mathrm{~V}$; and the sweep rate was $100 \mathrm{~V} \mathrm{~s}^{-1}$ 
$\mathrm{PEO}+\mathrm{LiCF}_{3} \mathrm{SO}_{3}$ films. Figure $2 \mathrm{a}$ shows that the film annealed at $40{ }^{\circ} \mathrm{C}$ presented a homogeneous surface without evident contrast. However, Fig. $2 b$ shows that a spherulitic morphology was formed with diameters of 50-100 $\mu \mathrm{m}$ for the film annealed at $100{ }^{\circ} \mathrm{C}$. The boundaries of the spherulitic phases were clearly observed. According to the phase diagram of $\mathrm{PEO}+\mathrm{LiCF}_{3} \mathrm{SO}_{3}$, the film should be in the $\mathrm{PEO}+\mathrm{P}\left(\mathrm{EO}_{3} \cdot \mathrm{LiCF}_{3} \mathrm{SO}_{3}\right)$ phase [15]. Since the film annealed at $40{ }^{\circ} \mathrm{C}$ did not show spherulitic morphology, the $\mathrm{LiCF}_{3} \mathrm{SO}_{3}$ phase may be separated from the PEO phase. Finer details could be seen using SEM. Tiny particles with $0.2-0.3 \mu \mathrm{m}$ in diameter could be observed for the $40{ }^{\circ} \mathrm{C}$ film (Fig. 2c, e), while a fibrous structure was formed during crystallization period for the $100{ }^{\circ} \mathrm{C}$ film (Fig. 2d, f). We broke the substrate in liquid nitrogen to examine the cross-sectional structure. A crosslinked fibrous structure was observed for the $100{ }^{\circ} \mathrm{C}$ film (Fig. 2h). A bundle of fiber consists of thousands of single nano-fiber, which provide nano-channels for ion migration to the P3HT layer in a defined direction.

Figure 3 shows the Raman spectra of $\mathrm{PEO}+\mathrm{LiCF}_{3} \mathrm{SO}_{3}$. Variations could be observed at both low wavenumbers (1,020-1,080 $\left.\mathrm{cm}^{-1}\right)$ corresponding to $\mathrm{S}=\mathrm{O}$ stretching modes [16], and high wavenumbers (2888.82, 2905.89, and $2939.9 \mathrm{~cm}^{-1}$ ) corresponding to $\mathrm{C}-\mathrm{H}$ stretch modes [17]. The $\mathrm{C}-\mathrm{H}$ stretching modes were more evident in the $100{ }^{\circ} \mathrm{C}$ film, but were too weak to be recognized in the $40{ }^{\circ} \mathrm{C}$ film, in which the peak at $2939.9 \mathrm{~cm}^{-1}$ became a shoulder (Fig. 3a). The peaks at $1033.87 \mathrm{~cm}^{-1}$ is attributed to the $\mathrm{S}=\mathrm{O}$ stretch in $\mathrm{LiCF}_{3} \mathrm{SO}_{3}$. The relative intensity between the $\mathrm{C}-\mathrm{H}$ and $\mathrm{S}=\mathrm{O}$ peaks reflects the $\mathrm{LiCF}_{3} \mathrm{SO}_{3}$ concentration and crystallization state of the $\mathrm{PEO}+\mathrm{LiCF}_{3} \mathrm{SO}_{3}$ film. For the $40{ }^{\circ} \mathrm{C}$ film, the intensity of $1033.87 \mathrm{~cm}^{-1}$ was 316.904 , while the intensity of $2890.14 \mathrm{~cm}^{-1}$ was 689.724 , making $I_{(\mathrm{C}-\mathrm{H})} / I_{(\mathrm{S}=\mathrm{O})}=2.18$. For the $100{ }^{\circ} \mathrm{C}$ film, the intensity of $1033.87 \mathrm{~cm}^{-1}$ was 258.252 while the intensity of $2888.82 \mathrm{~cm}^{-1}$ was 2201.38 , making $I_{(\mathrm{C}-\mathrm{H})} / I_{(\mathrm{S}=\mathrm{O})}=8.53$. This difference suggests that $\mathrm{LiCF}_{3} \mathrm{SO}_{3}$ was more effectively doped and dispersed into the electrolyte after annealing at $100{ }^{\circ} \mathrm{C}$. This result was consistent with the above experiments examining the film morphologies. Combining the results obtained from the SEM and Raman experiments, we could conclude that solubility $\mathrm{LiCF}_{3} \mathrm{SO}_{3}$ was increased and nano-fiber structure, which is favorable for ion migration, was formed for $\mathrm{PEO}+\mathrm{LiCF}_{3} \mathrm{SO}_{3}$ film annealed at $100{ }^{\circ} \mathrm{C}$.

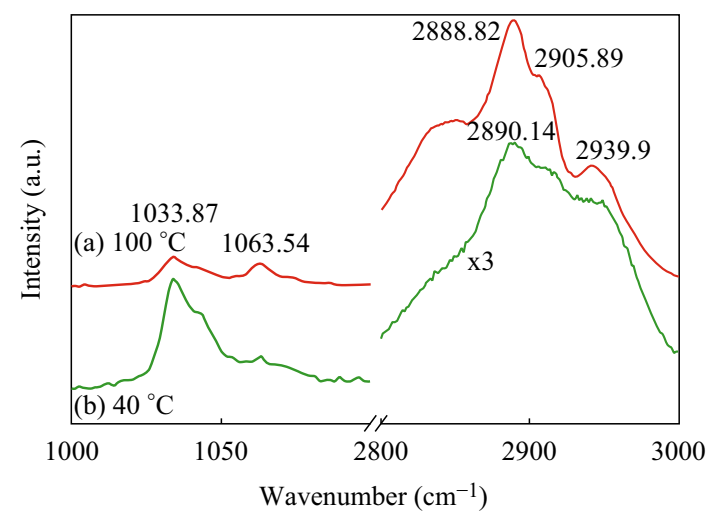

Fig. 3 Raman spectra of the $\mathrm{PEO}+\mathrm{LiCF}_{3} \mathrm{SO}_{3}$ films annealed at a $40{ }^{\circ} \mathrm{C}$ and b $100{ }^{\circ} \mathrm{C}$
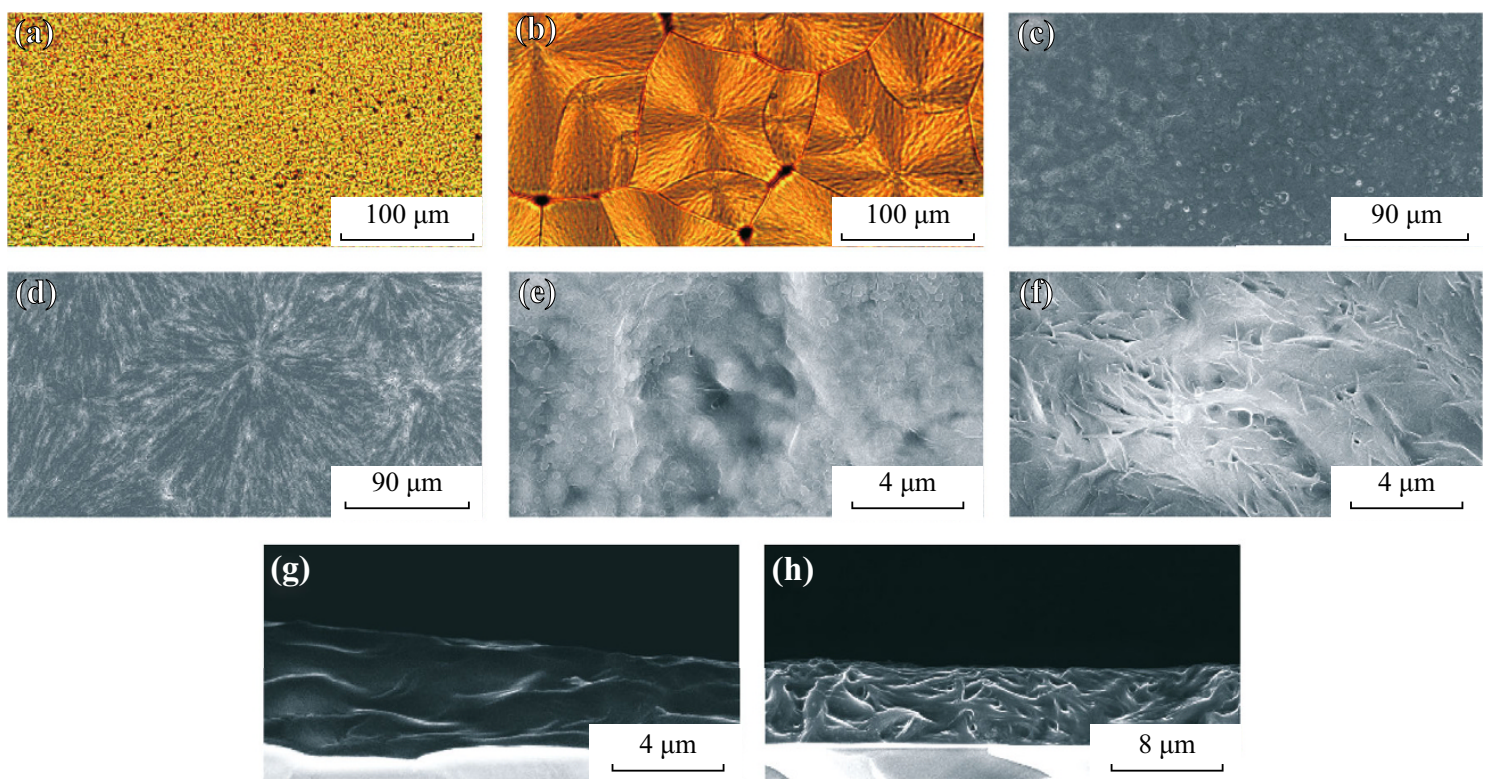

Fig. 2 Photomicrographs and SEM images of PEO $+\mathrm{LiCF}_{3} \mathrm{SO}_{3}$ films annealed at different temperatures: a, $\mathbf{c}, \mathbf{e}$, and $\mathbf{g}$ show the films baked at $40{ }^{\circ} \mathrm{C}$ and $\mathbf{b}, \mathbf{d}, \mathbf{f}$, and $\mathbf{h}$ show the films annealed at $100{ }^{\circ} \mathrm{C}$ 
$I-V$ properties in Fig. 1 could be easily understood on the base of microstructure analysis. High temperature annealing enhanced the ion solubility and formed nanochannels for fast ion migration. Such channels confined ions to move in ballistic trajectory. When a positive bias was loaded, the ions moved rapidly along the nano-channels and were injected into the P3HT layer. Since counter ion was scarce in P3HT and hard to be diffused into P3HT, an inverse electric field was established quickly, and then that resulted in NDR phenomena. This process can be illustrated in Fig. 4a. The low temperature annealed PEO contained less ions so that its conductivity was very low. In addition, this sample was totally amorphous and have strong coupling with polymer segments. The loaded bias has great difficult to establish inverse field at the interface, because ions would easily find other ways out of the nanochannels to relax the system.

Therefore, a positive pulse was used as the input signal, or stimulation, to check the feasibility of realizing synaptic behavior, since frequency selectivity is useful for synaptic computation [18-20]. Results are presented in Fig. 4b, c. Pulses were applied in a shape of saw-tooth with amplitude of $0.5 \mathrm{~V}$ and sweep rate of $100 \mathrm{~V} \mathrm{~s}^{-1}$. Figure $4 \mathrm{~b}$ shows that a single pulse response contains two parts: the current during the pulse width and the discharging current after the pulse. Since neither electrons nor holes were injected by the external field in the latter part, this process was dominated by inversely migrating ions. Therefore, the latter process could be used to mimic the ion kinetics in biosynapses related to memory and learning. Consequently, we examined weight modifications of responses to various pulse stimulations using the same measurement paradigm as used in neuroscience [20-22]. The ratio of a response to an arbitrary frequency compared with that of the baseline frequency is the value of the weight modification. In neuroscience, the peak in the discharge process relates to the migration of ions and release of transmitter-modifying synaptic plasticity which results in learning [23]. This peak, $I_{\mathrm{p}}$ in Fig. $4 \mathrm{~b}$, is usually treated as either an excitatory post-synaptic current (EPSC) or inhibitory post-synaptic current (IPSC) [20-22]. Thus, we used $I_{\mathrm{p}}$ to calculate the weight modification. In addition, we used the response to smaller frequency pulses $(1 \mathrm{~Hz})$ as the baseline standing for the resting state of bio-synapse. However, it corresponds in here to a 'read' pulse with a small pulse amplitude in studies of memory and learning devices [24, 25]. The ratio of the responses to pulses with higher frequency to the baseline was calculated as the weight modification of synaptic plasticity. The pulse waveform was unchanged but the frequency was modulated during measurement to resemble an action potential in biology or neuroscience.

The values of $I_{\mathrm{p}}$ were stabilized after enough stimulation pulses. The average value of the final five responses was used to calculate the weight modification. The HTC displayed apparent frequency selectivity (Fig. 4c) similar to the spike-rate-dependent-plasticity $[21,26]$, i.e., it was depressed when the frequency was ranged from 1 to $20 \mathrm{~Hz}$ (weight $<1$ ), but showed potentiation above $20 \mathrm{~Hz}$ (weight $>1$ ). The variation in weight modification resembles the CLO learning rule first proposed to solve the selectivity problem in physiology [27, 28], where the depression at low frequencies precipitated a modest rise in $\left[\mathrm{Ca}^{2+}\right][23,29,30]$. However, long-term plasticity was not obtained in our experiments because responses to the baseline frequency were unchanged after the cell was stimulated at frequencies higher than $1 \mathrm{~Hz}$. Thus, results in Fig. $4 \mathrm{c}$ suggested the cell could be used as band-pass filters in synaptic computation [18-20], but not in the learning process. In addition, the LTC was not depressed at low frequencies and its weight modification monotonically increased with pulse frequency (green circle line in Fig. 4c).

Such responses were repeatable and controllable as well as that had been demonstrated in our previous study. The responses in Fig. $4 \mathrm{~b}$ were stable during measurements.

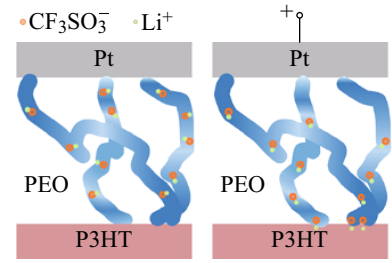

(a)

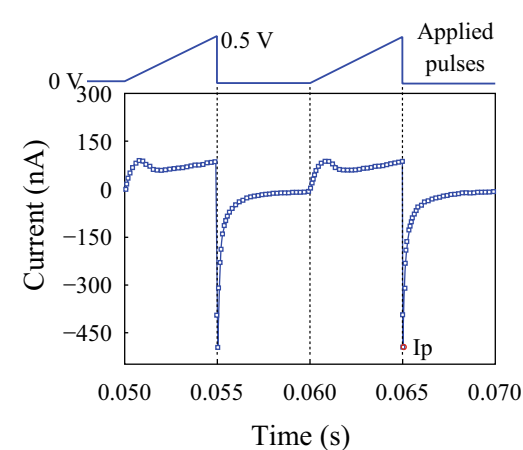

(b)

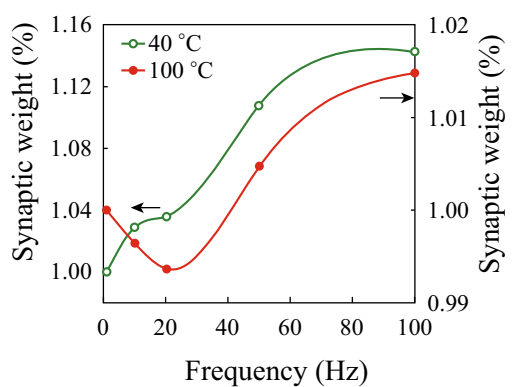

(c)

Fig. 4 a Schematic of the microstructure of the pristine cell and the cell loaded by positive bias, $\mathbf{b}$ Pulse responses to a saw-tooth wave for the HTC, $\mathbf{c}$ Variation of $I_{\mathrm{p}}$ with pulse number at a frequency of $100 \mathrm{~Hz}$ and weight modifications of the two cells 
There are several controlling factors, including sweep rate, amplitude, and measurement environment influencing the responses, the weight modifications, and the threshold values. Experiments demonstrated that normal sweep rate $\left(\sim 100 \mathrm{~V} \mathrm{~s}^{-1}\right)$ and extreme loading rate (rectangular pulse) [8] were capable of generating phenomena as shown in Fig. 4c. We did not observe depression when we used very high pulse amplitude $(\sim 2 \mathrm{~V})$. The transition from depression to potentiation should be related to input energy density, in which the NDR effects should have significant influences. Systematic experiments are being designed to clarify this issue and to give the principals of selecting pulse amplitude and loading rate. By the way, the exact values of responses and weight modifications fluctuated greatly with temperature and humidity different in seasons because our studies had performed in ambient environment. Stable measurement platform should be designed to focus on another scientific issue that how the polarity molecules, such as water, facilitate, or impede the ionic kinetics at the interface.

The above transition between depression and potentiation could be explained easily using the model proposed previously [8]. Pulse frequency modulated the timing of doping, de-doping, and re-doping in a pulse width, and then modulating the amount of ions (or de-doping strength) in the discharging process after a pulse ended. If NDR effect (i.e., de-doping still existed at the end of pulse width (or window), (i.e., corresponding low frequency stimulation), depression occurred. If NDR effect finished and re-doping were launched at the end of pulse width, (i.e., corresponding high-frequency stimulation), potentiation occurred. Here, the P3HT layer acted as ion selector and fibrous PEO provided ion ballistic transportation. Thus, the cell realized frequency selectivity. This process is completely adaptive as well as ion kinetics cross membrane in biosynapse, and the cell need not modify stimulation sign manually to obtain transition from depression to potentiation. Since the input amplitude and width are fixed, signals can be easily coded and decoded as well as that in information transport. Moreover, doping ions can be easily controlled in concentration and type, and the semiconducting polymer layer can be easily modified and doped in fabrication. Therefore, we supposed that hetero-junctions of organic semiconductor and electrolyte have extensive space in the application of information handling [18].

For the LTC samples, fibrous morphology did not form and the NDR did not appear. Therefore, there was not ionic selectivity at semiconducting polymer/electrolyte formed. Ions could diffuse laterally at the interface when strong input was loaded. Ionic kinetics was mainly dominated by behalves in electrolyte PEO. However, it had been found that no depression occurred in the pulses response of Lidoped PEO [8]. In this situation, electrical properties and pulse response resembled those in homogenous plasma system. This is the reason that the $20 \mathrm{~Hz}$ differentiate the depression and potentiation for HTC.

In summary, $\mathrm{Pt} / \mathrm{P} 3 \mathrm{HT} / \mathrm{PEO}+\mathrm{LiCF}_{3} \mathrm{SO}_{3} / \mathrm{Pt}$ cells were prepared and their microstructures were studied to determine the structural factors that influence the pulse responses. Nano-fibers were found in the electrolyte layer after annealed at high temperature, and the salt solubility was greatly enhanced. Ions migration could be confined in nano-channels along the fibers. This confinement was favorable and essential to form a strong inverse electric field at the $\mathrm{P} 3 \mathrm{HT} / \mathrm{PEO}+\mathrm{LiCF}_{3} \mathrm{SO}_{3}$ interface during pulse width, which was related to de-doping of the semiconducting layer. Input frequency modulated timing of doping, de-doping, and re-doping to result in synaptic-like frequency selectivity, i.e., depression at low frequency stimulation and potentiation at high stimulation. Our study suggested that ions migration in direction could be facilitated to signal handling.

Acknowledgments We thanks for helpful discussions with Prof. Sen Song in Department of Biomedical Engineering, School of Medicine, Tsinghua University. This work was supported by National Natural Science foundation of China (Grant Nos. 51371103 and 51231004), National Basic Research Program of China (Grant No. 2010CB832905) and National Hi-tech (R\&D) Project of China (Grant Nos. 2012AA03A706, 2013AA030801), the Research Project of Chinese Ministry of Education (No. 113007A).

Open Access This article is distributed under the terms of the Creative Commons Attribution License which permits any use, distribution, and reproduction in any medium, provided the original author(s) and the source are credited.

\section{References}

1. W.A. Henderson, D.M. Seo, Q. Zhou, P.D. Boyle, J.H. Shin, H.C. De Long, P.C. Trulove, S. Passerini, An alternative ionic conductivity mechanism for plastic crystalline salt-lithium salt electrolyte mixtures. Adv. Energy Mater. 2, 1343-1350 (2012). doi:10.1002/aenm.201200130

2. F.M. Gray, Polymer Electrolytes (RSC Materials Monographs, The Royal Society of Chemistry, Cambridge, 1997)

3. W. Gorecki, P. Donoso, C. Berthier, M. Mali, J. Roos, D. Brinkmann, M.B. Armand, NMR, DSC and conductivity study of the polymer solid electrolytes $\mathrm{p}(\mathrm{eo})\left(\mathrm{LiCP}+1 \mathrm{~F}_{2} \mathrm{P}+3 \mathrm{SO}_{3}\right) \mathrm{x}$. Solid State Ion. 28-30, 1018-1022 (1988). doi:10.1016/01672738(88)90323-2

4. A. van Zon, S.W. de Leeuw, A Rouse model for polymer electrolytes. Electrochim. Acta 46, 1539-1544 (2001). doi:10.1016/ S0013-4686(00)00750-7

5. O. Borodin, G.D. Smith, Mechanism of ion transport in amorphous poly(ethylene oxide)/LiTFSI from molecular dynamics simulations. Macromolecules 39(4), 1620-1629 (2006). doi:10. 1021/ma052277v

6. Z. Gadjourova, Y.G. Andreev, D.P. Tunstall, P.G. Bruce, Ionic conductivity in crystalline polymer electrolytes. Nature 412, 520-523 (2001). doi:10.1038/35087538 
7. Y. Wang, B. Li, J.Y. Ji, W.H. Zhong, Controlled $\mathrm{Li}^{+}$conduction pathway to achieve enhanced ionic conductivity in polymer electrolytes. J. Power Sources 247(1), 452-459 (2014). doi:10. 1016/j.jpowsour.2013.08.137

8. F. Zeng, S.H. Lu, S.Z. Li, X.J. Li, F. Pan, Frequency selectivity in pulse responses of $\mathrm{Pt} /$ poly(3-hexylthiophene-2,5-diyl)/polyethylene oxide ${ }^{+} \mathrm{Li}^{+} /$Pt hetero junction. PLoS ONE 9, e108316 (2014). doi:10. 1371/journal.pone.0108316

9. A. Adamatzky, L. Chua, Memristor Networks (Springer, Cham Heidelberg, New York, 2014)

10. J.J. Yang, D.B. Strukov, D.R. Stewart, Memristive devices for computing. Nat. Nanotechnol. 8, 13-24 (2013). doi:10.1038/ nnano. 2012.240

11. C. Zamarre-o-Ramos, L.A. Camu-as-Mesa, J.A. Pérez-Carrasco, T. Timothée Masquelier, T. Serrano-Gotarredona, B. LinaresBarranco, On spike-timing-dependent-plasticity, memristive devices, and building a self-learning visual cortex. Front. Neurosci. 5, 26 (2011). doi:10.3389/fnins.2011.00026

12. G. Indiveri, E. Chicca, R. Douglas, A VLSI array of low-power spiking neurons and bistable synapses with spike-timing dependent plasticity. IEEE Trans. Neural Netw. 17(1), 211-221 (2006). doi:10.1109/TNN.2005.860850

13. F. Pan, S. Gao, C. Chen, C. Song, F. Zeng, Recent progress in resistive random access memories: materials, switching mechanisms, and performance. Mater. Sci. Eng. R 83, 1-59 (2014). doi:10.1016/j.mser.2014.06.002

14. C.K. Machens, Building the human brain. Science 338, 1156-1157 (2012). doi:10.1126/science. 1231865

15. C.D. Robitaille, D. Fauteux, Phase-diagrams and conductivity characterization of some peo-lix electrolytes. J. Electrochem. Soc. 133(2), 315-325 (1986). doi:10.1149/1.2108569

16. C.P. Rhodes, R. Frech, Cation-anion and cation-polymer interactions in $(\mathrm{PEO})(n) \mathrm{NaCF}_{3} \mathrm{SO}_{3} \quad(n=1-80)$. Solid State Ion. 121(1-4), 91-99 (1999). doi:10.1016/S0167-2738(98)00534-7

17. C. Guo, J. Wang, H. Liu, J.Y. Chen, Hydration and conformation of temperature-dependent micellization of PEO-PPO-PEO block copolymers in aqueous solutions by FT-Raman. Langmuir 15(8), 2703-2708 (1999). doi:10.1021/la981036w

18. L.F. Abbott, W.G. Regehr, Synaptic computation. Nature 431, 796-803 (2004). doi:10.1038/nature03010
19. Z. Rotman, P.Y. Deng, V.A. Klyachko, Short-term plasticity optimizes synaptic information transmission. J. Neurosci. 31(41), 14800-14809 (2011). doi:10.1523/JNEUROSCI.3231-11.2011

20. D.L. Brody, D.T. Yue, Release-independent short-term synaptic depression in cultured hippocampal neurons. J. Neurosci. 20(7), 2480-2494 (2000)

21. S.M. Dudek, M.F. Bear, Homosynaptic long-term depression in area cal of hippocampus and effects of n-methyl-d-aspartate receptor blockade. PNAS 89(10), 4363-4367 (1992). doi:10. 1073/pnas.89.10.4363

22. G.Q. Bi, M.M. Poo, Synaptic modifications in cultured hippocampal neurons: dependence on spike timing, synaptic strength, and postsynaptic cell type. J. Neurosci. 15, 10464 (1998)

23. S.N. Yang, Y.G. Tang, R.S. Zucker, Selective induction of LTP and LTD by postsynaptic $\left[\mathrm{Ca}^{2+}\right]$, elevation. J. Neurophysiol. 81, 781 (1999)

24. T. Chang, S.H. Jo, W. Lu, Short-term memory to long-term memory transition in a nanoscale memristor. ACS Nano 5(9), 7669-7676 (2011). doi:10.1021/nn202983n

25. S.Z. Li, F. Zeng, C. Chen, H. Liu, G.S. Tang, S. Gao, C. Song, Y.S. Lin, F. Pan, D. Guo, Synaptic plasticity and learning behaviours mimicked through $\mathrm{Ag}$ interface movement in an $\mathrm{Ag} /$ conducting polymer/Ta memristive system. J. Mater. Chem. C 1 , 5292-5298 (2013). doi:10.1039/c3tc30575a

26. G. Rachmuth, H.Z. Shouval, M.F. Bear, C.S. Poon, A biophysically-based neuromorphic model of spike rate- and timingdependent plasticity. PNAS 108(49), E1266-E1274 (2011). doi:10.1073/pnas.1106161108

27. L.N. Cooper, M.F. Bear, The BCM theory of synapse modification at 30: interaction of theory with experiment. Nat. Rev. Neurosci. 13, 798-810 (2012). doi:10.1038/nrn3353

28. L.N. Cooper, F. Liberman, E. Oja, Theory for the acquisition and loss of neuron specificity in visual-cortex. Biol. Cybern. 33(1), 9-28 (1979). doi:10.1007/BF00337414

29. M.F. Bear, L.N. Cooper, F.F. Ebner, A physiological-basis for a theory of synapse modification. Science 237, 42-48 (1987). doi:10.1126/science.3037696

30. D. Neveu, R.S. Zucker, Postsynaptic levels of $\left[\mathrm{Ca}^{2+}\right]_{\mathrm{i}}$ needed to trigger LTD and LTP. Neuron 16(3), 619-629 (1996). doi:10. 1016/S0896-6273(00)80081-1 